\title{
Uma educadora, diretora, produtora audiovisual em sua experiência na TV universitária
}

Marília Franco

Professora do Departamento de Cinema, Rádio e TV da ECA/USP.

E-mail: marilia.franco@gmail.com

Nasci pouco antes da televisão, mas logo um aparelho chegou em casa, graças a um tio que trabalhava na fábrica dessas caixinhas mágicas. Engraçada a sensação que ela me causou - parecia criada para me satisfazer, tal o interesse que me provocava tudo que ela exibia, de futebol e boxe, a teatro de vanguarda, passando pela música, seriados, programas infantis e, até, pela publicidade.

Assistir à TV tornou-se um ritual, com local determinado - a sala de visitas - e horários marcados. Para esse ritual se reunia a telefamília nos finais de semana, sobretudo para a transmissão do futebol nas tardes de sábado e de domingo. Não era tão difícil disciplinar as crianças, pois o período de emissão era restrito e os canais se limitavam a dois ou três (isso em São Paulo e Rio, pois em outros estados havia um só canal), e a sintonia nem sempre era boa em todos. A vinheta Já é hora de dormir, da propaganda dos cobertores Parahyba, era a voz de comando para a criançada ir para a cama.

Mas eu não sabia que minha ligação com a TV se tornaria tão séria e profunda.

\section{FAZENDO ESCOLA E FAZENDO POLÍTICA}

Quando pensava em fazer faculdade, minha vontade inicial era cursar Arquitetura, mas minha deficiência com a matemática não me permitiu realizar esse sonho. Comecei a me preparar para o vestibular de Psicologia sem nenhuma empolgação, quando foram abertas as inscrições para a então Escola de Comunicações Culturais - ECC, hoje, Escola de Comunicações e Artes, a famosa ECA. Não tive, então, a menor dúvida de que esta seria minha casa. Depois de um vestibular com provas de redação, tradução de textos e conhecimentos gerais, ingressei no curso de Cinema, numa turma de 45 alunos.

A ECC era uma festa. Uma boa-nova na USP para alguns e um curso considerado não muito sério para outros. Tínhamos aulas comuns a todos os cursos 
- Biblioteconomia, Jornalismo, Rádio e Televisão, Cinema, Relações Públicas e Teatro - num auditório do térreo do edifício da Antiga Reitoria, assistidas por cerca de 200 alunos, alguns recém-saídos do colegial, outros já cursando os últimos anos de diferentes cursos, como Engenharia e Ciências Sociais, e, ainda, profissionais experientes que ingressavam na universidade buscando a oficialização de uma formação universitária. As aulas específicas de cada curso eram dadas no $1^{\circ}$ andar, onde hoje funciona a Rádio USP.

Isso foi em 1967, quando o Brasil caminhava para a fase mais escura da ditadura militar e o movimento estudantil estava em ebulição, somando-se a outros movimentos contra a ditadura que ferviam nos ambientes da arte e da cultura. Chegando à escola, pela manhã, tomávamos conhecimento de onde deveríamos comparecer à noite - se no Bexiga, na região dos teatros, ou na Rua Maria Antonia, onde ficava a Faculdade de Filosofia, Ciências e Letras da USP, pólo de irradiação das ordens do movimento estudantil.

Em 1968, inauguramos a primeira crise da ECA. Pressionado pelos alunos e pelo clima geral da universidade, o diretor - Julio Garcia Morejón - afastou-se do cargo. Mantivemos a escola tomada pelos alunos e nessa situação realizou-se o Encontro da UNESCO coordenado por Enrico Fulchignoni, com a presença de Roberto Rossellini, Edgar Morin, o cubano Alfredo Guevara, entre outras figuras internacionais. Dentre as estrelas locais estavam Glauber Rocha, Gustavo Dahl, Luiz Sérgio Person. Todos recebidos por nossos mestres e companheiros, Rudá de Andrade, chefe do Departamento de Cinema, Paulo Emílio Salles Gomes e Jean Claude Bernardet.

$\mathrm{O}$ verdadeiro espírito ecano, no entanto, mostrava-se nas reuniões da $\mathrm{Co}$ missão Paritária de professores e alunos, instrumento de decisões universitárias inaugurado nessa época. Jamais me esquecerei da convivência com Miroel Silveira e seus biscoitos, com a beleza física e intelectual de Lupe Cotrin Garraud, com a elegância de Alfredo Mesquita, com a timidez e a simpatia de Virgilio Noya Pinto, a sinceridade mineira de Sábato Magaldi, o interminável e indispensável conhecimento jurídico de Clóvis Garcia. Esses e todos os professores com os quais compartilhávamos as decisões sobre a crise da escola e da universidade foram figuras determinantes em nossa formação ética e política, sempre temperada de muito carinho e camaradagem. Nosso trabalho era denso, mas sem pompa e circunstância, que não caberiam na ECA.

\section{A AMBÍGUA POSIÇÃO DA ECA ANTE O DESENVOLVIMENTO DA TV}

O curso de Rádio e TV nunca foi dos mais concorridos no vestibular, embora os graduados fossem duramente disputados, especialmente pela TV Cultura, cujas primeiras imagens foram ao ar nesse difícil ano de 1968. Hoje integrado ao curso de Cinema e Vídeo, recentemente transformados em curso superior do Audiovisual, o curso de Rádio e TV sempre careceu de recursos técnicos e bons projetos pedagógicos, mas contou com professo- 
res históricos e formou gente muito boa que, ainda hoje, está no mercado televisivo, trabalhando com a mídia mais evidente e estridente da cultura brasileira.

Assim, havia esse grande paradoxo: enquanto o mundo acadêmico encarava a televisão como uma das estratégias da ditadura para dominação - uma espécie de circo moderno servido como a sobremesa do pão do povo -, a ECA não parava de formar profissionais para atuar e se destacar na consolidação da primeira e verdadeira indústria cultural de nosso País. O resultado foi que, enquanto em diversos cursos da Escola, como Teatro e Cinema, Jornalismo e Biblioteconomia, desenvolviam-se profundos estudos e práticas pedagógicas, no tocante à televisão, faziam-se apenas leituras críticas, condenando a TV e relegando-a a uma visão técnica e empírica. Nem sequer como curiosidade a universidade acompanhou, histórica e reflexivamente, o desenvolvimento dessa mídia que consolidou a produção de bens imateriais da melhor qualidade técnica e estética do País.

A implantação de uma verdadeira indústria de produtos audiovisuais brasileiros, com sistemas e métodos profissionais de produção e circulação, construída e consolidada nacional e internacionalmente pela Rede Globo, nunca foi tema de pesquisa e reflexão acadêmica com verdadeira curiosidade científica. Houve, sim, farta e delirante produção opinativa contra (copiosa) e a favor (sempre tímida).

Não posso, neste depoimento, deixar de citar a honrosa exceção do Núcleo de Estudos da Telenovela ${ }^{1}$, que, entre incêndios e outras perdas, faz um grande trabalho de documentação, pesquisa e reflexão, e os pesquisadores quase solitários que desenvolvem e publicam seus trabalhos, com pouco reconhecimento dos seus pares.

\section{O SURGIMENTO DAS TVS UNIVERSITÁRIAS}

A oportunidade da criação dos canais universitários de televisão, transmitidos pelos sistemas de cabo, foi um presente dos legisladores que as universidades brasileiras não pediram e que tiveram de aprender como utilizar. Ela foi gerada pela Lei Federal n. 8.977, de 6 de janeiro de 1995, conhecida como Lei da TV a Cabo, que, em seu artigo 23, instituiu os chamados Canais Básicos de Utilização Gratuita, que as operadoras devem disponibilizar, sem custos para os assinantes ou para os provedores de conteúdo dos canais. Esse artigo diz que deve haver "um canal universitário, reservado para o uso compartilhado entre as universidades localizadas no município ou municípios da área de prestação do serviço"?.

E embora, em 1967, já funcionasse a TV Universitária do Recife, vinculada à Universidade Federal de Pernambuco, entre outras experiências com programação produzida em canais abertos e UHF, o boom de televisões universitárias começou em 1997, quando já se consolidava um número expressivo de cursos universitários de Rádio e TV por todo o Brasil. Em 10 de novembro, entrou no
1. O Núcleo de Pesquisa em Telenovelas (NPTN) da Escola de Comunicações e Artes (ECA) da USP foi o primeiro grupo acadêmico do mundo formado com o objetivo de pesquisar e documentar a produção da telenovela. O Núcleo está ativo e foi reaberto. Maiores informações são obtidas pelo telefone (11) 3091-4373 [N.E.]

2. <http://www.senado. gov.br/tv/conheca/legislacao/lei8977capi.asp>. 
ar o Canal Universitário - CNU, com sede em São Paulo, formado por nove universidades. A USP fazia parte desse grupo, sendo responsável pela implantação da TV à Coordenadoria de Comunicação Social - CCS, que já abrigava o Jornal da USP, a Rádio USP, a Revista USP, o USP on-line e outras atividades de comunicação.

No momento em que foi dada ao prof. dr. Celso de Barros Gomes, então coordenador da CCS, a tarefa de preparar a criação da nova mídia, eu entrei na história, como coordenadora do UNIVÍDEO/CECAE - Coordenadoria Executiva de Cooperação Universitária e Atividades Especiais - e da produção de dois vídeos institucionais muito bem-sucedidos, encomendados pela reitoria. Comecei participando das reuniões para a criação do canal universitário, tendo ficado em minhas mãos a elaboração de um projeto para a TV USP. Então, foi uma graduada em cinema, da primeira turma da ECA e sempre professora de cinema, que acabou escrevendo o projeto e implantando a TV USP, com a participação brilhante e dedicada de vários alunos de graduação dos cursos de Rádio e TV e de Cinema e Vídeo da ECA. O projeto foi entregue ao prof. Celso em 11 de julho de 1997, aprovado pelo Conselho Universitário em outubro e a TV USP entrou no ar, através do CNU, em 10 de novembro de 1997.

Tenho impressão de que foi a mais veloz criação de uma TV de que se tem notícia. Também foi uma TV que entrou no ar sem estúdio, sem equipamentos, sem condições de produção, mas com uma garra e uma criatividade quase sem limites. Mérito dos estagiários. A mim cabia acreditar e implementar as idéias com uma habilidade burocrática que até hoje custo a acreditar que tenha sido possível exercer.

\section{INSPIRAÇÕES}

A visão que sempre tive da importância e do papel de uma TV dentro de qualquer universidade está sintetizada no projeto da TV USP, que propõe uma janela através da qual tornará visíveis suas atividades de ensino, pesquisa e extensão, possibilitando ao cidadão contribuinte conhecer e participar, com opiniões e perguntas, das atividades que financia através de seus impostos.

Para isso, a produção traçou as seguintes direções conceituais:

- pluralismo;

- excelência;

- interatividade;

- valorização da construção do conhecimento;

- formação cultural das novas gerações;

- resposta ao investimento da sociedade.

Era necessário alcançar esses objetivos respeitando a estética de TV sem trair a busca do aprofundamento, da excelência e da responsabilidade que emanam das 
A decisão para enfrentar esses deliciosos desafios foi propor uma espécie de diálogo entre a mídia aberta e a acadêmica. Fazer de nosso olhar mais demorado sobre a realidade o charme e a substância de nossa programação. Enfrentar os temas do cotidiano com a especialização de nossas abordagens. Não ter patrocínios e compromissos de audiência abria uma liberdade de criação e experimento que quase nos embriagava. A universidade oferecia especialistas, opiniões substanciosas, conhecimento histórico para qualquer que fosse o tema de preocupação da população. Pudemos dialogar com a política, a ciência, a arte, as grandes tragédias e as pequenas comédias diárias, oferecendo uma leitura diferenciada, contraditória e rica.

A realidade nos pautava, mas jamais tomamos os modelos da mídia aberta como orientação. Procuramos construir uma fala em profundidade, ainda que ágil, leve e interessante.

Buscamos sempre respeitar a inteligência e o discernimento de nosso espectador, evitando entonações que fechassem questão em torno dos temas. Preferimos oferecer uma pluralidade de pontos de vista para que nosso público pudesse construir sua opinião.

Esses eram os parâmetros que norteavam a construção de nossos programas e que guiavam a criação dos formatos e a organização da grade.

Olhando para dentro da universidade entendíamos que a TV USP precisava dar voz a todos os segmentos que a compunham. Seguindo esse princípio, criamos nossos primeiros programas: Delta Pi, a voz dos estudantes, e Olhar $d a$ USP, a voz dos docentes. Também produzíamos Panorama, programa de variedades que falava de atualidades culturais, artísticas, científicas na USP e na cidade de São Paulo. Buscamos a voz dos funcionários, mas a experimentação não foi muito longe. Considero isso uma grande dívida da TV USP. Também produzimos muitos especiais em vários formatos, sobretudo documentários, que tinham quase tom autoral, dada a forma como eram criados e realizados pela equipe.

Nos programas de grade, isto é, aqueles mais permanentes, tive uma atuação bastante decisiva, desde a construção do conceito, a escolha do formato, a definição do nome (Olhar da USP foi batizado por mim e Delta Pi, escolha dos estagiários) até a decisão de muitas pautas e abordagens. Os programas especiais eram propostos por alguém da equipe e, se aprovados, passavam a ser coordenados e dirigidos pelo proponente. Por isso o caráter quase autoral.

O labor coletivo, no entanto, constituía nosso grande estímulo. A TV USP era nossa. Cada um zelava por seu papel e responsabilidade, e o intercâmbio de idéias e opiniões era permanente. Havia coordenação, papéis institucionais diferenciados e sobre mim pesava o grande compromisso de criar e manter a credibilidade do projeto e da equipe. Internamente éramos um coletivo alegre e laborioso, consciente da oportunidade histórica que estávamos abraçando. Essa foi minha mais profunda inspiração durante os cinco anos em que respondi pela direção da TV USP. 


\section{AS DIFERENÇAS ENTRE CANAIS PÚBLICOS E PRIVADOS}

Trabalhar num canal universitário é atuar na televisão pública, o que tem suas peculiaridades. Mesmo sendo uma concessão pública, a TV privada possui um dono, uma voz e um ponto de vista. Há uma fonte clara e definida de interesses, de negócios, de políticas. Sem fazer juízo de valor sobre esse poder que representa ter um canal de TV, ele é o determinante da função desse canal no conjunto dos negócios desse dono e será a partir desse ponto que se estabelecerá o papel do público espectador. São essas relações entre o interesse privado do dono e a satisfação da audiência que irão mover a roda da fortuna dos canais privados.

A TV pública é uma concessão do Estado ao Estado. O financiamento vem dos impostos, portanto, o público é o dono dessa TV. Quem, no entanto, representa e aponta seus interesses e pontos de vista? Os funcionários públicos responsáveis pela gestão e pela programação? Há Conselhos nas Fundações que administram as TVs públicas no Brasil. Há notáveis reitores e outros homens públicos nesses Conselhos, mas não existe um dono, no sentido em que este é o definidor do interesse de tal TV na relação com o espectador.

As TVs públicas exemplares no mundo - a britânica BBC e a japonesa NHK - têm inúmeras diferenças de inserção pública e de gestão, mas possuem um ponto em comum: seus departamentos de pesquisa são tão grandes e importantes quanto os departamentos de produção. E a pesquisa não é de audiência, mas com a audiência, isto é, a pergunta não é se estão assistindo ao canal, e sim o que querem e precisam assistir no canal. Essas respostas definem as pautas, as grades e as avaliações de satisfação do público.

As TVs públicas no Brasil mal se interessam pelos resultados quantitativos de audiência, que dirá investir em investigação qualitativa.

Desse modo, os planos de programação e produção ora são definidos por funcionários mais ou menos aptos a essa função, ora ficam à mercê dos interesses do governo que está recolhendo os impostos e distribuindo sua aplicação. Já tivemos bons momentos de TV pública, na TV Cultura de São Paulo, por exemplo. Igualmente tivemos e temos muitos momentos em que a TV pública é muito mais do governo que do público.

\section{A FUNÇÃO PEDAGÓGICA DA MÍDIA}

A questão da pedagogia das coisas e das ações precisa de uma revisão urgente. Costumamos atribuir apenas à educação formal a tarefa pedagógica de transformar os seres em cidadãos conscientes e produtivos. Nessa medida entendemos que a educação escolar, com sua ação pedagógica, é boa em si.

No entanto o que temos visto, com uma freqüência inquietante, é que a rua, a mídia, a vida e a morte andam indicando e transformando as ações de muitas pessoas, sobretudo crianças e jovens. Incluindo entre esses os que fre- 
qüentam escolas formais. Há um claro ensinamento, uma pedagogia aleatória, vinda de uma fonte genérica, invisível e inimputável a que chamamos sociedade, governo, mundo moderno, caos social.

Desde os anos 1920, igreja, escola e família julgaram e condenaram o cinema como mau exemplo para a sociedade, sobretudo para crianças e jovens. Não perceberam a pedagogia sedutora e eficiente existente nessa má influência e deixaram de pesquisar e refletir sobre esse potencial pedagógico entrevisto, mas não reconhecido.

A indústria cultural, no entanto, entendeu magnificamente as condições de transformação contidas nessa pedagogia do gosto, do prazer e da sedução, e se consolidou, diversificou-se em rádio, revistas, televisão e agora internet.

Os Estados expansivos pautaram suas ações políticas na extensão do alcance territorial da pedagogia das mídias para abrir caminhos a seus avanços políticos e econômicos. Chegamos a tal poder invasivo da pedagogia das mídias que no dia 18 de outubro de 2005, na Unesco, se firmou a Convenção sobre a Proteção e a Promoção da Diversidade das Expressões Culturais. Um tratado, debatido e combatido por longo tempo, permitindo às nações signatárias o direito de garantir e defender políticas culturais nacionais. Ao todo 133 países assinaram a Convenção e dois países não firmaram: Estados Unidos e Israel. Abstiveramse Austrália e Kiribaty.

O absurdo dessa situação deve fazer com que reflitamos sem preconceitos e com sinceridade sobre o real papel e sentido da pedagogia no mundo contemporâneo. Que dispamos o termo de seu uniforme escolar e o vejamos brincando livre ou disfarçado pelas linhas e entrelinhas do cinema, dos jornais, da televisão, da publicidade - forma mais eficaz de pedagogia midiática jamais desenvolvida.

Não buscamos o pedagógico. Ele se apresenta em cada ação estética e cultural que desenvolvemos. O que devemos procurar é o sentido de responsabilidade pessoal e social que isso representa.

\section{AS DIFICULDADES PEDAGÓGICAS DAS TVS UNIVERSITÁRIAS}

O exercício de funções de pesquisa de linguagem, de inovação de processos, de desenvolvimento de novas formas de comunicação audiovisual são importantes funções pedagógicas das TVs universitárias, conforme pude apreender de minha experiência na direção da TV USP. No entanto, os entraves a sua plena realização são resultado da parcimônia dos recursos financeiros, mas também da miopia acadêmica em relação à mídia.

Os canais universitários têm buscado patrocínios e apoios de empresas como forma de sustentar seus custos, na maior parte das vezes bancados pelos orçamentos internos das universidades, públicas ou particulares. Pouco sucesso ou durabilidade têm essas parcerias. No entanto, a liberdade de criar e expe- 
rimentar que a falta de compromissos com patrocinadores traz é o que pode garantir que as TVs universitárias cumpram um papel inovador no desenvolvimento da comunicação audiovisual.

Paradoxo difícil de entender e mais difícil ainda de defender ante as administrações das universidades.

Há ainda uma outra função que essas TVs têm tido, também de difícil equilíbrio: a interação com os cursos de Rádio e TV, Jornalismo e outros de comunicação social. A dificuldade maior é distinguir e separar as atividades de ensino e de laboratório. No ensino o aluno tem de ter o direito de demorar mais a realizar as práticas e mesmo de errar nos projetos e execuções. No laboratório, que pode ser uma TV universitária, ele precisa de atitude, de responsabilidade e de ritmo profissionais. Os erros não podem ir ao ar, nem se pode adiar a exibição de um programa porque não ficou pronto.

Uma TV universitária é como uma residência médica. Há a supervisão de professores e outros profissionais, mas o diagnóstico e o remédio são resolvidos pelo residente.

\section{A DIREÇÃO DE UMA TV UNIVERSITÁRIA}

O diretor de uma TV universitária propõe, orienta, supervisiona e responde por tudo o que acontece no desenvolvimento da produção e da difusão dos programas. Gerencia e garante as condições administrativas, financeiras e técnicas para a realização da programação. Analisa, avalia e planeja para garantir o presente, pensando o tempo todo no futuro. Necessita de sensibilidade, já que não há verba para pesquisa de audiência, de perceber o que está dando certo na programação, o que precisa melhorar e o que tem de mudar, acabar, recriar.

Deve estar permanentemente atualizado e atento às inovações tecnológicas e saber a hora em que ainda dá para agüentar a velha máquina e quando a mudança é indispensável para garantir a qualidade mínima do trabalho.

Precisa manter a equipe motivada e unida. Tem de propor disciplina e hierarquia, sem tolher a iniciativa e a criatividade, pois sem isso a TV não irá para a frente; também ter plena consciência e eterna vigilância de que o desentendimento no set de gravação aparece na tela, das formas mais inesperadas.

Necessita de entusiasmo e paciência, cautela e ousadia, firmeza e sinceridade. E saber criticar e ouvir críticas. E tem de apagar incêndios e fazer improvisos como se fossem normas do cotidiano.

\section{QUALIDADE EM TV}

Qualidade é uma palavra a ser revisitada com o mesmo desassombro que se deve ter ao falar de pedagógico. É um valor relativo que precisa ser pesado e medido a partir de projeto e objetivos. 
Um programa de baixaria, que tenha sido pensado e produzido com esse objetivo e que tenha grande repercussão, não deixa de ter qualidade de projeto e de gestão, ainda que o resultado cultural e social seja lamentável. Um grande concerto, minuciosamente planejado e soberbamente executado, que custe caríssimo para produzir e tenha uma audiência de traço, pode ter alta qualidade estética e cultural, mas quase nenhuma gerencial.

O tão famoso, decantado e bem-sucedido Padrão Globo de Qualidade foi arquitetado e desenvolvido com mãos de ferro e articulação minuciosa por três profissionais de excepcionais qualificações, com talentos específicos. A visão e a competência gerencial de Walter Clark, a capacidade de direção artística de Daniel Filho e o perfeccionismo de acabamento de José Bonifácio de Oliveira Sobrinho, o Boni. Quantos anos, no entanto, foram necessários para ajustar o funcionamento desse triunvirato e que capacidade alucinada de trabalho e dedicação foi exigida dos três para o projeto se consolidar. Além do substancial aporte financeiro.

Pensando em TV universitária, eu diria que uma de suas qualidades deve ser o ritmo mais lento de abordar e apresentar os temas, abrindo clima e espaço para o espectador assimilar e construir opinião. Essas qualidades serão insuportáveis numa TV comercial. As qualidades conservadoras, no melhor sentido do termo, de um programa como Viola minha viola de Inezita Barroso só cabem numa TV pública como a Cultura. Seria insustentável num canal universitário e mais ainda num canal comercial.

O cosmopolitismo que se espera de um Fantástico ficaria ridículo num canal comunitário, e o falatório dos canais legislativos e do Judiciário, qualidades intrínsecas desses canais, são absolutamente insuportáveis em qualquer outro.

A TV segmentada, oferecida pelos canais a cabo e por antena parabólica, transformou definitivamente o panorama, o gosto e os valores da televisão na sociedade contemporânea. Mudou a competição uniformizada pela audiência quando só havia canais abertos. A competitividade deixou de ser por imitação. $\mathrm{O}$ zapping com o controle remoto deslocou a idéia de gancho que prende a audiência.

A TV segmentada é monolítica na sua gestão empresarial, pois é uma só operadora que oferece a diversidade. Assim sua qualidade está assentada sobre a variedade, a fragmentação, a explosão de explorações temáticas verticais. Tudo de esporte, de notícia, de cinema, de vendas, de canais internacionais, de programas infantis, de videoclips, de et ceteras. Essa é sua qualidade.

A TV aberta compete na horizontal. Notícias nos mesmos horários, novelas disputando segundos de audiência, programas infantis com os mesmos formatos, para as senhoras as mesmas receitas culinárias, artesanatos e cosméticos. Ao contrário do frenesi do zapping estimulado pelas segmentadas, é a preguiça e a inutilidade de mudar de canal que comandam a relação com as TVs abertas.

Diante desse panorama, é uma temeridade fazer qualquer afirmação categórica de qualidade em relação à TV contemporânea. 


\section{ENCERRAMENTO}

A TV USP que fiz, com a equipe que consegui agregar, deixou-me um doce sabor de ter realizado um sonho que nunca sonhei e de ter cumprido tal tarefa/dever com uma alegria que foi um privilégio.

Nós éramos felizes e sabíamos!

Resumo: Com base em sua experiência como criadora e diretora da TV USP, Marília Franco discorre sobre a criação das TVs universitárias, sobre seus desafios, dificuldades e possibilidades pedagógicas. Fala sobre a importância da televisão no Brasil e a carência de uma pesquisa científica sobre seu papel histórico.

Palavras-chave: televisão, TV universitária, TV USP, direção, qualidade.
Abstract: Based in her experience as creator and director of TV USP, Marília Franco discourses on the creation of universitary televisions, its challenges, difficulties and pedagogic possibilities. She talks on the importance of television in Brazil and the lack of a scientific research on its historical role.

Keywords: television, universitary television, TV USP, direction, quality. 